\title{
Review Article \\ Diabetes Mellitus, Cognitive Impairment, and Traditional Chinese Medicine
}

\author{
S. W. Seto, ${ }^{1}$ G. Y. Yang, ${ }^{1}$ H. Kiat, ${ }^{2,3,4}$ A. Bensoussan, ${ }^{1}$ Y. W. Kwan, ${ }^{5}$ and D. Chang ${ }^{1}$ \\ ${ }^{1}$ National Institute of Complementary Medicine, University of Western Sydney, Campbelltown, NSW 2560, Australia \\ ${ }^{2}$ Faculty of Medicine, University of New South Wales, Kensington, NSW 2052, Australia \\ ${ }^{3}$ School of Medicine, University of Western Sydney, Locked Bag 1797, Penrith, NSW 2751, Australia \\ ${ }^{4}$ Faculty of Medicine and Health Sciences, Macquarie University, NSW 2109, Australia \\ ${ }^{5}$ School of Biomedical Sciences, The Chinese University of Hong Kong, Shatin, Hong Kong \\ Correspondence should be addressed to D. Chang; d.chang@uws.edu.au
}

Received 5 January 2015; Accepted 15 April 2015

Academic Editor: Andrea Tura

Copyright (C) 2015 S. W. Seto et al. This is an open access article distributed under the Creative Commons Attribution License, which permits unrestricted use, distribution, and reproduction in any medium, provided the original work is properly cited.

\begin{abstract}
Diabetes mellitus (DM) is a metabolic disorder affecting a large number of people worldwide. Numerous studies have demonstrated that DM can cause damage to multiple systems, leading to complications such as heart disease, cancer, and cerebrovascular disorders. Numerous epidemiological studies have shown that DM is closely associated with dementia and cognition dysfunction, with recent research focusing on the role of DM-mediated cerebrovascular damage in dementia. Despite the therapeutic benefits of antidiabetic agents for the treatment of DM-mediated cognitive dysfunction, most of these pharmaceutical agents are associated with various undesirable side-effects and their long-term benefits are therefore in doubt. Early evidence exists to support the use of traditional Chinese medicine (TCM) interventions, which tend to have minimal toxicity and side-effects. More importantly, these TCM interventions appear to offer significant effects in reducing DM-related complications beyond blood glucose control. However, more research is needed to further validate these claims and to explore their relevant mechanisms of action. The aims of this paper are (1) to provide an updated overview on the association between DM and cognitive dysfunction and (2) to review the scientific evidence underpinning the use of TCM interventions for the treatment and prevention of DM-induced cognitive dysfunction and dementia.
\end{abstract}

\section{Introduction}

Diabetes mellitus (DM) is a metabolic disorder characterised by an increase in plasma glucose level due to insulin deficiency and/or resistance that can lead to damage to multiple organs. Currently, approximate 347 million people are suffering from DM worldwide and the number will continue to increase. There are two types of DM: type 1 diabetes mellitus (T1DM) and type 2 diabetes mellitus (T2DM). T1DM is caused by the destruction of the pancreatic $\beta$-cells due to an autoimmune reaction, leading to absolute insulin deficiency, whilst T2DM is characterised by insulin resistance, where the body fails to produce an appropriate physiological response to circulating insulin. T2DM accounts for approximately $90 \%$ of all DM cases with the prevalence increasing with age. Tremendous effort has been invested to understand the complications of DM and its impact on vision loss, neuropathy, and cardiovascular diseases; however, DM-induced cognitive dysfunction is seldom addressed and is not as well understood.

Since life expectancy has been markedly prolonged with advances in medicine, it has been suggested that the incidence of T2DM and dementia would increase as the population ages $[1,2]$. Indeed, several epidemiological studies have shown that people with T2DM have a significantly higher risk of developing cognitive impairments and dementia when compared to those with normal blood glucose levels [3-5]. A recent population-based longitudinal study has shown that the relative risk of Alzheimer's diseases (AD) and vascular dementia $(\mathrm{VaD})$ in the $\mathrm{DM}$ population was 1.46 (95\% CI: 1.20-1.77) and 2.5 (95\% CI: 2.1-3.0), respectively, when compared to people without DM [6]. Moreover, DM has 
been suggested to be an individual risk factor for dementia $[7,8]$, independent of other established risk factors, such as hypertension and atherosclerosis $[8,9]$.

The brain pathology underlying cognitive dysfunction is heterogeneous and is highly complicated. Traditionally, AD is considered as the major diagnosis of dementia [10]; however numerous clinical-pathological studies have suggested a significant contribution of cerebrovascular diseases to cognitive decline $[11,12]$. Although the exact pathophysiology of DMmediated dementia has not been fully elucidated, existing evidence has shown that both cerebrovascular changes and neurodegeneration are implicated in the development and progression of DM-mediated cognitive dysfunction [5]. To date, there are no DM-specific treatments to prevent or ameliorate cognitive dysfunction. Nevertheless, numerous reports have highlighted the therapeutic potential of antidiabetic therapies in the treatment and prevention of cognitive dysfunction [1315]. In the largest randomized controlled trial to date, the ACCORD-MIND study, it was shown that the decline in total brain volume was significantly reduced in the intensive glycemic control group, compared to the standard glycemic control group. Although the cognitive outcomes were not different, the effect of glycemic control in preserving cerebral structure cannot be denied [16]. Findings from these studies have clearly indicated that treatments targeting DM could be a novel strategy to prevent dementia development and potentially to slow down the progression of cognitive dysfunction.

Through the advances in pharmacological therapy, many oral antidiabetic agents have become available. Interestingly, oral antidiabetic drugs such as thiazolidinedione and metformin have been shown to have beneficial effects to slow the progression of dementia in both clinical and animal studies [17, 18]. However, many of these pharmaceutical agents are associated with various undesirable side-effects, such as weight gain, fluid retention, and increased risk for heart failure, limiting their compliance and utility in clinical practice. Traditional Chinese medicine (TCM), including Chinese herbal medicines (CHM) and acupuncture, has been used for thousands of years for the management of disease, maintenance of health, and prolongation of life expectancy. Accumulated evidence suggests that many CHMs and their active ingredients possess hypoglycemic properties and that some TCM interventions have beneficial effects in the treatment and prevention of DM and its complications, with minimal toxicity and fewer adverse reactions [19]. In addition, existing evidence has demonstrated the therapeutic potential of TCMs in DM-mediated cognitive dysfunction [20]. In this paper, we present a comprehensive review of current understanding of DM-mediated dementia and the scientific research on the use of TCMs for the management of cognitive dysfunction in DM.

\section{Association of Diabetes and Cognitive Dysfunction and/or Dementia}

Poor glycemic control has been associated with progression of cognitive dysfunction [21]. An increasing number of studies have reported an acceleration of cognitive decline in patients with DM, independent of common cardiovascular risk factors $[8,22]$. To date, DM is recognised as an independent risk factor for the development of cognitive dysfunction. In a meta-analysis based on twenty-five studies, it was estimated that T2DM patients have 1.5-fold greater risk of cognitive dysfunction and 1.6-fold increased risk of dementia, when compared to people without diabetes [23]. Similarly, a recent report has shown a 1.5-fold higher risk of $\mathrm{AD}$ in people with diabetes than those without diabetes [6]. Most reports so far have suggested an increased risk of global cognitive dysfunction in diabetes $[6,23,24]$, while some reports showed more selective cognitive impairment, mainly affecting learning, mental speed, and visuospatial process [25-27]. It is important to point out that the discrepancy between these studies may simply be due to the variation of neurocognitive testing, such as age, education, sex, history of other illnesses, and the duration/severity of diabetes [28, 29].

Many complications of diabetes, such as retinopathy, lower limb ulcers, and atherosclerosis, usually take years to develop before becoming clinically apparent. However, cognitive function decrement has been observed in the early stage of T2DM [30]. In children with T1DM, deficits in cognitive development, including vocabulary, block design, general intelligence, speed of processing, and learning, have been observed as early as 2 years after the onset of T1DM [31]. These findings suggested that deficits in regulation of blood sugar level, even at an early stage, would have detrimental effects on cognitive function. Interestingly, recent studies have demonstrated that elevated blood glucose levels may be a risk factor for impaired cognitive function leading to dementia, even among people without diabetes $[32,33]$ highlighting the relationship between high blood glucose level and dementia outcome.

There is ample evidence from neuropsychological studies reporting that people who have DM also suffer from mild cognitive impairment (MCI). Longitudinal studies have shown that approximate $55 \%$ of patients with MCI developed probable Alzheimer's dementia over 3 years $[34,35]$ and the progression rate reached $100 \%$ after 9.5 years [36]. It has been suggested that DM patients have $50 \%$ higher chance of developing Alzheimer's disease than those without DM [6]. A longitudinal study has also shown a relationship between diabetes and incidence of MCI [37]. Progression of MCI to dementia has been shown to be markedly accelerated by diabetes in elderly subjects who were either cognitively intact or diagnosed with MCI at baseline [38]. Brain imaging studies have provided direct evidence to support DM-mediated MCI and dementia [39, 40]. Resting-state functional magnetic resonance imaging (rs-fMRI) studies have revealed abnormalities in amplitude of low-frequency fluctuations (ALFF) in T2DM patients in multiple brain regions. These present as decreased ALFF in the bilateral middle temporal gyrus and left fusiform gyrus and increased ALFF in bilateral cerebellum posterior lobe and right cerebellum culmen [41]. Moreover, recent studies have shown that alternation of ALFF and reduced connectivity of the hippocampus are associated with the presence of diabetic vascular disease and poor cognitive performance in T2DM patients [42, 43]. Although the mechanism between MCI and the increased risk of 


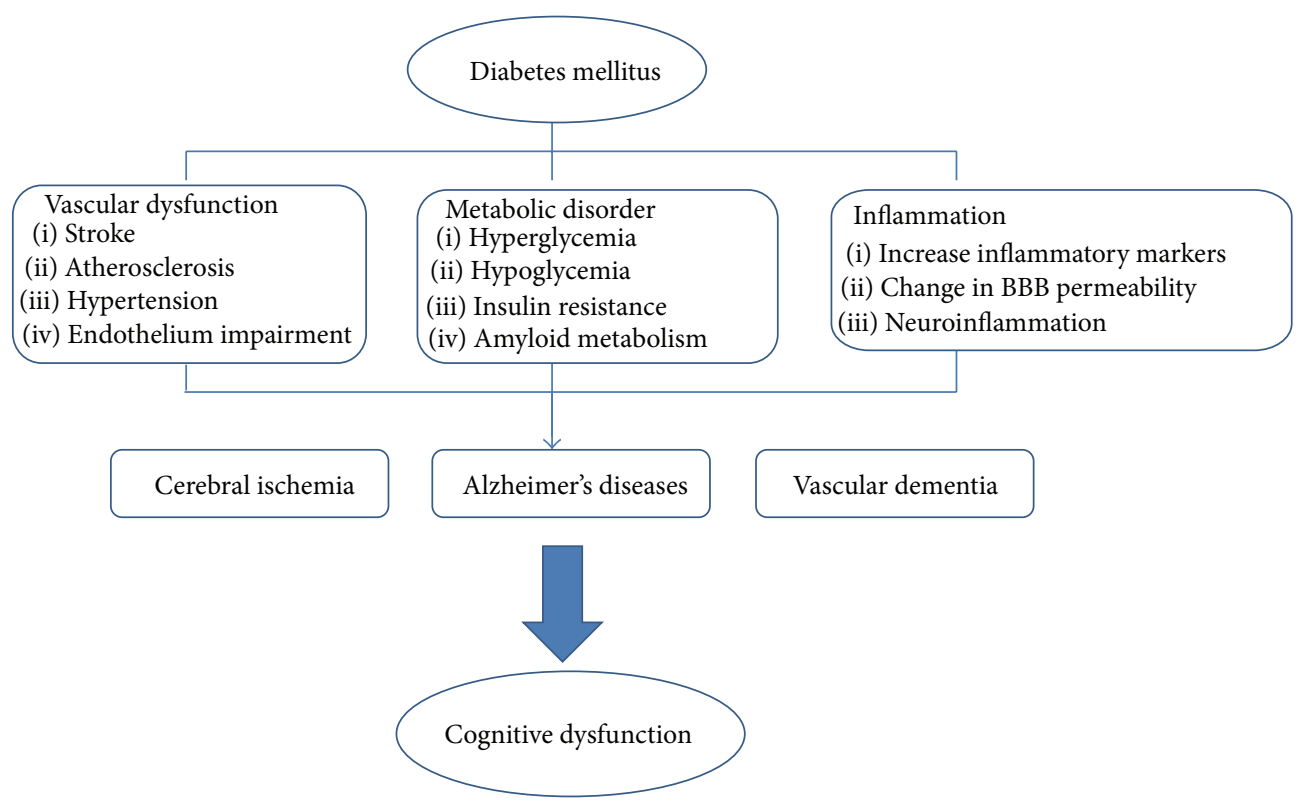

FIGURE 1: Mechanism of DM-mediated cognitive dysfunction.

dementia under DM is not fully understood, it has been suggested that the DM-mediated MCI and dementia are not likely to form a continuum, given the difference in etiologies and risk factors between MCI and dementia [44, 45].

People suffering from DM over a long period have been shown to express an elevated level of dementia $[46,47]$. There are an extensive number of studies examining the effect of DM on cognitive functions in elder population [48-50]. It has been shown that the prevalence of dementia in T2DM patients increased over age, from $2.4 \%$ in the age group of $65-$ 76 and $5 \%$ in $76-85$ to $8.3 \%$ for patients over 85 years of age [51]. Several studies have also reported an increased incidence of dementia in individuals who were diagnosed with DM in midlife after an extended follow-up of 25-35 years [7]. However, the exact effect of midlife against late-life DM onset on cognitive impairment and dementia remains to be clarified.

\section{Pathophysiology of Cognitive Dysfunction and/or Dementia in Diabetes}

The mechanisms underlying the development of cognitive dysfunction in diabetes have not been fully elucidated. Many hypotheses have been suggested based on the pathophysiological mechanisms through which diabetes might affect the initiation and progression of the pathology of dementia [52]. These proposed mechanisms include various diabeticspecific factors or signalling pathways that may influence cognitive functioning, such as hyperglycemia, insulin deficiency, microvascular complications, and inflammation. In this section, we will highlight some of the risk factors and possible mechanisms related to cognitive dysfunction in diabetes (Figure 1).

3.1. Vascular Dysfunction. Vascular complications, including atherosclerosis, hypertension, stroke, and vascular comorbidity, are closely associated with DM. Recent studies have reported that vascular complications are likely to be an important determinant of cognitive dysfunction and dementia [11]. Increased cerebral infarcts and reduction of amyloid-beta load were observed in older DM patients compared to nondiabetics [53]. A meta-analysis of longitudinal studies suggested that there is a stronger association of vascular-related cognitive impairment than $\mathrm{AD}$ with $\mathrm{DM}$ patients [6]. Interestingly, less Alzheimer's-like pathology has been observed, but more ischemic lesions in T2DM patients with a clinical diagnosis of dementia have been observed [54]. Indeed, an increasing number of studies are suggesting that the reduction of cerebral perfusion plays a significant role in the development of $\mathrm{AD}$ [55], supporting the hypothesis that cerebrovascular pathology such as stroke predisposes cognitive decline and dementia development. The detrimental effects of DM on cognitive function in vascular dementia have been demonstrated in a recent preclinical study. Kwon et al. showed that exacerbated cognitive functions caused by diabetes were mediated via augmentation of neuronal cell death in the hippocampus through CREB/BDNF signalling pathway in an animal model of vascular dementia [56].

Hypertension has been shown to be a significant risk factor for poor cognitive performance in both T1DM and T2DM patients $[57,58]$. In addition to hypertension, atherogenic dyslipidemia is another common vascular risk factor in DM [59]. Dyslipidemia contributes to atherosclerosis development [60] and has been found to increase risk of dementia in diabetes [61]. Moreover, reduced cerebral blood flow [62], upregulation of inflammatory cytokines $[63,64]$, endothelial dysfunction [65], and abnormalities in cerebral capillaries [66] have been demonstrated in patients with diabetes. Changes in cerebral vasculature by these factors are closely associated with stroke and brain damage, including brain infarct and white matter lesions [67], contributing to 
cognition deterioration in diabetes. Given the complex pathophysiology of vascular complications in diabetes, more research is required to explore the exact mechanisms around how these DM-related vascular risks contribute to cognitive decline and dementia. However, majority of current findings have confirmed the association of vascular risk factors and cognitive decrements in diabetes and support the belief that predominant cerebrovascular pathology in diabetes could aggravate cognitive functioning.

3.2. Metabolic Abnormalities. Blood glucose levels are regulated by the endocrine system involving multiple organs and signalling molecules and pathways. Upset of this precisely regulated process could lead to imbalance of blood glucose level, resulting in organ damage. Although the exact mechanisms behind the association between DM and cognitive impairment or dementia are unclear, studies have shown that it is a multifactorial process where metabolic condition plays a significant role.

3.2.1. Hyperglycemia. Chronic high blood glucose levels have been shown to have negative effects on cognitive functions and brain structure [68]. Hyperglycemia is a characteristic in both T1DM and T2DM. Numerous studies have demonstrated a close relationship between glucose intolerance and cognitive decrements and dementia [24, 69, 70]. It has been shown that people with poor glycemic control, with glycosylated hemoglobin (HbAlc) higher than $7.0 \%$, have a 4 -fold higher risk of developing cognitive impairment [71]. Similarly, an inverse association of $\mathrm{HbAlc}$ and cognitive function such as working memory, learning, and executive functioning has been observed in T2DM patients [72]. The results of these studies highlight the contribution of poor glycemic control in cognitive function deterioration process. Multiple toxic effects of hyperglycemia on the brain, such as formation of advanced glycated end products (AGEs), generation of reactive oxygen species (ROS), and activation of polyol, diacylglycerol, and hexosamine pathways, have been suggested.

It has been shown that hyperglycemia leads to enhanced formation of AGEs [73]. AGEs have been shown to contribute to microvascular complications, accelerated amyloid-beta deposition and senile plaque formation $[9,71]$. A preclinical study has demonstrated that increased cerebral AGEs expression is associated with cognitive dysfunction in diabetic mice [74]. Similarly, increased AGEs levels have been observed in $\mathrm{AD}$ patients with $\mathrm{T} 2 \mathrm{DM}$, when compared to nondiabetic $\mathrm{AD}$ patients [75]. Moreover, AGEs lead to ROS generation via activation of a RAGE cell surface receptor for AGEs, which in turns leads to neuronal injury $[76,77]$.

It is well established that oxidative stress is implicated in both the onset and progression of diabetes and its complications. It has been shown that cognitive deficit caused by hyperglycemia in diabetic rat is associated with an increase in ROS levels and reduction of antioxidant levels [78, 79]. In addition, increased ROS generation has been shown to activate various cellular signalling pathways, such as the polypol pathway, protein kinase $\mathrm{C}$ activation, and increase of glucose shunting via the hexosamine pathway, all of which are related to neuronal injury and cerebral damage [80]. Interestingly, it was shown that administration of antioxidants could reverse the cognitive dysfunction in the diabetic rats $[78,79]$, suggesting a potential therapeutic target for DM-mediated cognitive impairment.

3.2.2. Hypoglycemia. Sufficient glucose supply is vital for normal brain function and it is well established that hypoglycemia has detrimental effects on the brain [81, 82]. Repeated hypoglycemic episodes are a common side-effect in patients who receive intensive insulin therapy for diabetes [83]. In animal studies, it has been shown that exposure to low blood glucose levels can cause cerebral energy failure, neuronal necrosis, and brain damage leading to a flat electroencephalograph and cognition dysfunction [81]. In human autopsy studies, multifocal or diffuse necrosis of the cerebral cortex, basal ganglia, and hippocampus was observed in patients who died of hypoglycemia [82]. A dose-response relationship between the occurrence of severe hypoglycemic episodes and risk of dementia development has been reported in a retrospective study involving 16,667 T2DM patients [84]. Although contradicting results have been reported by some studies $[85,86]$, arguing that tolerance to a hypoglycemic state can be developed in patients exposed to hypoglycemia chronically, the effect of hypoglycemia on some high-risk groups cannot be ignored. For example, it has been shown that impairment of memory functioning is strongly correlated with severe hypoglycemia in T1DM patients [87].

3.2.3. Changes in Insulin and Amyloid Metabolism. The blood glucose level is regulated by insulin, a hormone generated by the beta cells in the pancreas. Traditionally, it was believed that the brain is an insulin independent organ; however, recent studies have suggested otherwise [88]. It has been shown that insulin is actively transported across the blood brain barrier [89] and is also produced locally in the brain [90]. Furthermore, insulin receptors are expressed in the hippocampus and the cortex, indicating its functional role in the brain [91]. In addition, being a regulator of food intake and energy homeostasis [88], insulin also plays a role in memory and learning [92]. Changes in insulin levels and receptor sensitivity could lead to deficits in cognitive function [93]. In $\mathrm{AD}$, impairments of cerebral insulin receptors activation and elevated insulin level in the CSF have been reported [94], indicating the contribution of insulin in cognitive decline and dementia development.

Hyperinsulinemia is a common characteristic of T2DM and has been identified as a risk factor for cognitive dysfunction and dementia progression $[95,96]$. It has been suggested that hyperinsulinemia is associated with reduction of amyloid metabolism, due to downregulation of insulin-degrading enzyme (IDE) levels in the brain [97]. IDE is responsible for the degradation of insulin and amyloid- $\beta$ peptide $(\mathrm{A} \beta)$. Therefore reduced IDE levels would lead to $A \beta$ accumulation in the brain, contributing to $\mathrm{AD}$ and cognitive impairment [98]. Hyperphosphorylation of tau protein is another pathological hallmark of $\mathrm{AD}$. It has been suggested that inhibition of insulin-mediated pathways can lead to hyperphosphorylation of tau and $\mathrm{A} \beta$ production, via activation of the glycogen synthase kinase 3 (GSK3) signalling $[99,100]$. 
3.3. Inflammation. Inflammation has been implicated in the onset of DM and progression of its complications [95]. It has been suggested that people suffering from DM are under a state of subclinical chronic inflammation [101, 102]. Numerous proinflammatory markers and cytokines, such as Creactive protein (CRP), tumour necrosis factor- (TNF-) $\alpha$, interleukin- (IL-) $1 \beta$, and IL-6, have been shown to be upregulated in both T1DM and T2DM [103]. Many of the proinflammatory markers have been associated with cognitive decline and dementia development [104]. Given the fact that many of these inflammatory markers found in DM patients are closely associated with the pathogenesis of $\mathrm{AD}$ [105], there is an increasing interest in the link between DM and dementia. Yaffe et al. reported that impaired cognitive functions were observed in DM patients with elevated CRP and IL-6 levels, but not in patients with normal levels of these markers [71].

Inflammation has been suggested to induce cerebral changes via multiple mechanisms. Firstly, it has been shown that chronic inflammation in DM can induce changes in blood brain barrier (BBB) permeability [106]. Increase in BBB permeability has been observed in brain biopsies from $\mathrm{AD}$ patients [107]. Moreover, increased BBB permeability can also allow access of toxic substances and metabolites into the brain, leading to cerebral damage [108]. Secondly, neuroinflammation is a well-established factor in the development of cognitive decline, dementia, and other neurodegenerative diseases $[109,110]$. It has been demonstrated that inflammatory cytokines can cause activation of glia cells leading to neuronal damage. For example, TNF- $\alpha$ has been shown to induce hippocampal dysfunction, via activation of the $J \mathrm{NK}$ and the $\mathrm{I} \kappa \mathrm{B} \alpha$ kinase $/ \mathrm{NF} \kappa \mathrm{B}$ signalling pathway [111-113]. Finally, inflammation plays a central role in the development of complications in vasculature, including stroke [114], contributing to cognitive impairment and dementia development as discussed in Section 3.1.

\section{The Use of TCM in the Treatment of Cognitive Dysfunction and Dementia in DM Patients}

Given the fact that DM is now an established risk factor for cognitive dysfunction and dementia, there is an increasing interest in targeting DM for the treatment of cognitive decline and dementia. Several studies suggested that oral antidiabetic drugs such as thiazolidinedione and metformin could offer therapeutic benefits to reduce DM-related cognitive dysfunction in both patients and animal models [17, 18]. A recent study demonstrated that glycemic control using empagliflozin significantly prevented cognitive impairment via attenuation of cerebral oxidative stress and increase in cerebral brain-derived neurotropic factor in a T2DM mouse model [115]. This highlighted the potential of antihyperglycemic agents in the treatment of T2DM-related cognitive dysfunction. However, some clinical studies have demonstrated rather limited and inconsistent benefits of these glucose lowering agents in limiting cognitive decline and dementia development [14-16]. Furthermore, the risks associated with the use of antiglycemic/insulin therapies have raised the concerns regarding the long-term safety and effectiveness of these interventions for the management of DM-induced cognitive dysfunction and dementia $[84,85]$. For example, hypoglycemia is commonly observed in T1DM patients with tight glycemic control and in advanced T2DM patients [116, 117]. Although intensive insulin therapy has shown to successfully control glycemia and reduce vascular complications in DM patients, several reports have highlighted possible neuronal damage and cognitive impairment due to the incidence of hypoglycemia associated with the insulin therapy [118].

Traditional Chinese medicine (TCM) has been used to treat DM for over thousands of years. A large number of TCM interventions belonging to several key modalities (such as herbal medicine, acupuncture, and Taichi) have been used for the management of DM and its complications [19] (Table 1). According to traditional Chinese medical system, Chinese practitioners, who often adopt a holistic approach in treating their patients, manage diabetes through integrated care: nourishing and strengthening the body's functions rather than focusing solely on blood glucose control $[119,120]$. Despite a lack of scientific validation of the TCM interventions for diabetes, the accumulated evidence has demonstrated some promising results in relieving the symptoms and complications of diabetes [121, 122]. In this section, we will firstly review the current clinical findings of TCMs used for DM-related cognitive dysfunction and then highlight some of the potential mechanisms underlying the TCM effects on the condition.

4.1. Clinical Studies. Numerous clinical studies have demonstrated the beneficial effects of TCM interventions on cognitive dysfunction and dementia. Data from a meta-analysis suggest that TCM interventions appear to be a safer and more effective treatment for vascular dementia, based on 31 randomised clinical trials comparing 1605 patients on TCM treatments with 1263 patients on Western medicine or placebo [123]. It has been suggested that sleep apnea hypopnea syndrome (SAHS) patients with T2DM have a higher risk of cognitive decline than the nondiabetic SAHS patients [116]. Interestingly, in a clinical study, a 2-week treatment with DanHong Injection, consisting of extracts of Salvia miltiorrhiza and Carthamus tinctorius L., significantly improved the Montreal Cognitive Assessment (MoCA) score, especially in the executive function and memory domains, in 86 SAHS patients with T2DM. Although blood glucose levels were not examined in this study, the results indicate that DanHong Injection could improve cognitive function in T2DM patients [124]. Another clinical study in 36 T2DM patients has demonstrated that combined Huang Qi (Radix Astragali) and Chuanxiong (Ligusticum Wallichii) injections over 30 days significantly reduced blood glucose levels and improved cognitive function, whilst the standard pharmaceutical care with antidiabetic agents in the control group only reduced the blood glucose levels, indicating that the herbal formula may provide therapeutic benefits to DM patients beyond its blood glucose lowering property [125].

In a clinical trial involving 164 diabetic patients with complicated coronary heart disease (CHD), it was shown 
TABLE 1: A summary of key TCM modalities used of the treatment of diabetes.

\begin{tabular}{|c|c|c|}
\hline TCM modalities & Mechanisms of action & References \\
\hline \multicolumn{3}{|c|}{ Herbal medicine } \\
\hline Radix Astragali & $\begin{array}{l}\text { Improved hyperglycemia status, insulin sensitivity, and } \\
\text { glucose uptake }\end{array}$ & {$[126]$} \\
\hline \multirow[t]{2}{*}{ Salvia Miltiorrhiza } & $\begin{array}{l}\text { Reduce oxidative stress and improved insulin sensitivity } \\
\text { index }\end{array}$ & {$[127]$} \\
\hline & Reduced serum oxLDL and sVCAM-1 & {$[128]$} \\
\hline \multirow[t]{2}{*}{ Panax ginseng } & $\begin{array}{l}\text { Reduced blood glucose and insulin level and inhibited } \\
\text { angiogenesis }\end{array}$ & {$[129]$} \\
\hline & Reduced blood glucose level and improved glucose tolerance & {$[130]$} \\
\hline Semen Coicis & Hypoglycemic effect, no effect on HbAlc level & {$[131]$} \\
\hline Dioscoreae rhizoma & Hypoglycemic effect and improved insulin sensitivity & {$[132]$} \\
\hline Ganoderma lucidum & $\begin{array}{l}\text { Reduced serum glucose level and suppressed hepatic PEPCK } \\
\text { gene level }\end{array}$ & {$[133]$} \\
\hline \multirow[t]{2}{*}{ Cinnamomi Cassiae } & $\begin{array}{l}\text { Increased insulin sensitivity, reduced lipids level, and } \\
\text { hypoglycemic effect }\end{array}$ & {$[134]$} \\
\hline & Antioxidative effect and reduced blood glucose level & {$[135]$} \\
\hline Radix Platycodi & Increased insulin sensitivity and GLUT4 translocation & {$[136]$} \\
\hline Ligusticum chuanxiong & $\begin{array}{l}\text { Reduced blood glucose level, improved renal function, and } \\
\text { decreased VEGF level }\end{array}$ & {$[137]$} \\
\hline Gynostemma pentaphyllum & $\begin{array}{l}\text { Increase SOD and GSH-px activities and improved glycemic } \\
\text { control }\end{array}$ & {$[138]$} \\
\hline Potentilla chinensis & Antioxidative and antihyperglycemic effects & [139] \\
\hline \multicolumn{3}{|c|}{ Acupuncture } \\
\hline $\begin{array}{l}\text { Acupuncture to } 6 \text { points (Zhongwan, Tianshu, } \\
\text { Qihai, Ganshu, Pishu, and ShenShu) }\end{array}$ & Reduced blood glucose level, no effect on body weight & {$[140]$} \\
\hline $\begin{array}{l}\text { Electroacupuncture at Zusanli (ST-36) and } \\
\text { Zhongwan (CV-12) }\end{array}$ & $\begin{array}{l}\text { Reduced blood glucose level via stimulation of the } \\
\text { cholinergic nerves }\end{array}$ & {$[141]$} \\
\hline Acupuncture at points GB34 and GB39 & Decreased ischemic in brain and neuronal protective effect & {$[142]$} \\
\hline $\begin{array}{l}\text { Electroacupuncture at ear points and to body } \\
\text { points }\end{array}$ & $\begin{array}{l}\text { Reduced glucose level and increased serum insulin and } \\
\text { c-peptide levels }\end{array}$ & {$[143]$} \\
\hline \multicolumn{3}{|c|}{ Taichi } \\
\hline 1-hour session twice a week for 12 weeks & $\begin{array}{l}\text { Improved glucose control, balance, and neuropathic } \\
\text { symptoms }\end{array}$ & {$[144]$} \\
\hline 1.5-hour session three times a week for 12 weeks & $\begin{array}{l}\text { Improved health-related quality of life such as physical } \\
\text { functioning and body pain }\end{array}$ & {$[145]$} \\
\hline 19 Taichi movements, twice a week for 6 months & $\begin{array}{l}\text { Declined fasting glucose and HbAlc level, better quality of } \\
\text { life in mental health }\end{array}$ & {$[146]$} \\
\hline 1 hour per day, 5 days a week for 14 weeks & Improved glycemic control and lowered serum TG level & {$[147]$} \\
\hline 12 weeks of Taichi exercise programme & $\begin{array}{l}\text { Decreased HbAlc level with increased Thl reaction and } \\
\text { blood IL-12 level }\end{array}$ & {$[148]$} \\
\hline
\end{tabular}

that while both isosorbide mononitrate $(20 \mathrm{mg}$, twice a day) and FufangDanshenDiwan (consisting of Salvia miltiorrhiza, Panax pseudoginseng var. notoginseng, and Dryobalanops aromatica Gaertn. f.) (270 mg, once daily) treatments for 16 weeks significantly improved the cardiac ischemia burden (as measured by 24-hour ambulatory ECG monitoring), improvements in insulin sensitivity and lipid metabolism indexes were only observed in patients received FufangDanshenDiwan. Moreover, the herbal formula was also shown to reduce $A \beta$ formation and improve cognitive function in the DM patients [149]. As mentioned in Section 3, increased oxidative stress and inflammation are closely associated with the cognitive dysfunction in DM patients. Li and Yeung have demonstrated that an 8-week treatment with Zhi Nao capsule consisting of extracts of Codonopsis pilosula, Polygonatum sibiricum, Ligusticum Wallichii, and Acorus tatarinowii significantly increased serum superoxide dismutase (SOD), reduced CRP level, and limited cognitive decline and dementia development in T2DM patients [150].

In China, it is not an uncommon practice to use integrative strategies, combining TCM and Western medicine interventions, in the treatment of DM and its complications [151]. Numerous studies have assessed the efficacy of the combined therapies to treat cognitive dysfunction in DM 
patients. Nao Xin Tong, a complex herbal formula (consisting of Radix Astragali, Salvia Miltiorrhizae, Angelicae Sinensis, Ligusticum Wallichii, Paeoniae Rubra, Flos Carthami Tinctorii, Gummi Olibanum, Resina Commiphorae Myrrhae, Ramulus Cinnamomi Cassiae, Buthus martensi, Lumbricus, and Hirudo seu Whitmaniae) has been shown to improve cognitive function in 32 stroke patients with T2DM [152]. In patients who received a combined therapy of alprostadil with Lao Xin Tong, a greater cognitive enhancing effect was observed when compared to the alprostadil only group [153]. In a clinical trial, $48 \mathrm{DM}$ patients with $\mathrm{VaD}$ were randomised to receive piracetam or piracetam plus oral ShengmaiDingzhi decoction (consisting of Pseudostellaria heterophylla (Miq.) Pax, Ophiopogon japonicus, Schisandra chinensis, Wolfiporia extensa, Polygala tenuifolia Willd., Acorus tatarinowii, Pinellia ternata (Thunb.) Breit, Semen Persicae, Panax pseudoginseng var. notoginseng, and Glycyrrhiza uralensis) over 60 days. The combined therapy group demonstrated greater improvements in the Activities of Daily Living Scale (ADLS) and the Scale of Elderly Cognitive Functions (SECF) when compared to that of the piracetam only group [154]. Several studies have demonstrated that a combined therapy of BushenQuyuYizhi decoction (consisting of Cistanche deserticola, Acorus tatarinowii, and Panax pseudoginseng var. notoginseng) with nimodipine produced a significantly greater effect than nimodipine alone on cognitive function $[155,156]$. In a more recent study conducted by Zhao et al., 85 patients with DM-mediated vascular cognitive dysfunction were allocated to receive a 6-month treatment of aspirin $(100 \mathrm{mg}$, once daily) or aspirin (100 mg, once daily) plus BushenQuyuYizhi decoction ( $2.5 \mathrm{~g}$ per day, orally), over 6 months. At the completion of the 6-month treatment, cognitive dysfunction was improved in both treatment groups. However, the cognitive improvement was only maintained in the combined therapy group 12 months after the treatment, indicating a potential long-term effect of the herbal intervention, possibly via enhancement of general health and limiting disease progression in the patients.

Electroacupuncture is a form of acupuncture by way of applying a small electric current between pairs of fine needles that are inserted into acupoints selected according to the TCM theory [157]. Numerous studies have shown positive effects of electroacupuncture on cognitive impairment [158]. Several recent studies have also demonstrated that electroacupuncture improved cognitive function and quality of life in diabetic patients $[159,160]$. Although the sample sizes were small (ranging from 25 to 32 patients) in these studies, the therapeutic potential of electroacupuncture should not be ignored and further investigations with a rigorous design are warranted.

4.2. Mechanisms of TCMs in Treating DM-Mediated Cognitive Dysfunction and Dementia. A large number of in vitro and in vivo preclinical studies have been conducted to assess the underlying mechanisms of TCM interventions in diabetesrelated cognitive dysfunctions. Reduced antioxidative levels and increased ROS generation are closely associated with the pathogenesis of diabetes and its complications. Antioxidant properties of CHMs have been demonstrated in numerous studies $[161,162]$. For example, green tea, which is commonly consumed in Eastern and Asian countries, contains of a mixture of plant polyphenols that possess antioxidative and radical-scavenging activities [163]. In obese KK-ay mice, green tea catechins reduced blood glucose levels and insulin resistance via inhibition of the TNF- $\alpha$-induced ROS generation [164]. It has also been shown that green tea catechins markedly suppressed memory regression in SAMP10 mice, a mouse model of brain senescence with cerebral atrophy and cognitive dysfunctions. Daily consumption of green tea catechins significantly reduced brain atrophy and suppressed DNA oxidative damage. These effects were associated with the improvement of plasma antioxidative activity caused by daily green tea consumption [165]. A recent study showed that green tea catechins remarkably ameliorated learning and memory impairments in a diabetic rat model, via the reduction of oxidative stress and nitric oxide modulation. In this study, green tea catechins also significantly reduced the blood glucose levels, indicating that green tea can suppress diabetesmediated cognitive dysfunction via both hypoglycemic and antioxidative effects [166]. Indeed, numerous other CHMs, such as berberine and ginsenoside, have been shown to reduce diabetes-mediated cognitive decline via reduction of oxidative stress $[167,168]$.

Tanshinol (TSL), a bioactive component of Danshen (Salvia miltiorrhiza), widely used for vascular disease [169], was shown to improve spatial working memory and attenuated vascular dementia in rats, via an increase in acetylcholine levels and reduction of acetylcholinesterase activity [170]. Tanshinone IIa (Tan IIa), another bioactive component of Danshen, was also shown to restore diabetes-induced nerve deficiency [171]. The regulation of the cholinergic neurotransmission in the brain plays a vital role in memory and cognitive function. Similar to TSL, several other herbal constituents, including lycopene, berberine, and curcumin, have been shown to ameliorate diabetes-related cognitive dysfunction, via protection of the cholinergic neurotransmission $[167,172$, 173].

In addition, several other mechanisms have been proposed as underlying the effect of CHMs on DM-mediated cognitive dysfunction, such as through reduction of AGEsmediated neuroinflammation and the downregulation of cerebral amyloid-beta $(\mathrm{A} \beta)$. For example, Danshensu, a bioactive component of Salvia miltiorrhiza, has been shown to improve learning and memory in diabetic mice via suppression of AGE-mediated neuroinflammation. These effects were independent of blood glucose, insulin, and glycosylated hemoglobin levels, indicating a direct neuroprotective and anti-inflammatory effect of Danshensu [174]. Liuwei Dihuang decoction (LWDHD), a well-established TCM formulation, consisting of six herbs (Rehmannia glutinosa Libosch., Cornus officinalis Sieb., Dioscorea oppositifolia L., Paeonia ostii, Alisma orientale (G. Samuelsson) Juz., and Poria cocos (Schw.) Wolf), has been shown to attenuate neural apoptosis and $\mathrm{A} \beta$ deposition in the hippocampus and cerebral cortex in a streptozotocin-induced diabetic rat model [175]. In addition, LWDHD also reduced blood glucose levels, decreased oxidative stress, and suppressed inflammation in hippocampus of the animals [175]. Interestingly, Chen et al. 
showed that administration of $\mathrm{ZiBuPiYin} \mathrm{recipe} \mathrm{(ZBPYR),}$ a modification of the Zicheng decoction (consisting of 12 herbs: Panax ginseng C. A. Meyer, Dioscorea opposita Thunb., Poria cocos (Schw.) Wolf, Paeonia lactiflora Pall., Salvia miltiorrhiza Bge., Dolichos lablab L., Nelumbo nucifera Gaertn., Acorus gramineus Soland., Polygala tenuifolia Willd., Santalum album Linn., Citrus maxima (Burm.) Merr. cv. Tomentosa, and Glycyrrhiza uralensis Fisch.), over a 6week treatment, prevented DM-associated cognitive decline in $\mathrm{db} / \mathrm{db}$ mice. The observed effect was possibly due to improving dendritic spin density and attenuating brain leptin and insulin signalling pathway injury [176]. Although these findings need to be confirmed in humans, it provides important preclinical data to support the potential benefits of TCM in preventing and slowing the development and progression of DM-associated cognitive dysfunction.

Data from the above studies have clearly indicated that the positive effects of CHMs could be mediated by multiple pathways and mechanisms. Combination therapy underpins the philosophy of CHMs, where patients are generally treated with multiherb formulations. Complex chemical mixtures of CHMs enhance therapeutic efficacy by facilitating synergistic action and/or ameliorating/preventing potential side-effects. The multicomponent and multitarget approach of CHMs makes them ideal therapies for disorders such as DMmediated cognitive dysfunction and dementia, which have multifactorial/multisystem pathophysiological components.

\section{Summary and Future Directions}

Substantial effort has been invested to understand the effects of diabetes on cognitive decline and dementia in the past decade. Recent studies have identified the risk factors and possible mechanisms underlying the pathogenesis of the DM-mediated cognitive dysfunction. By taking advantage of recent advancements in these processes, it is possible to develop better therapies for DM-related cognitive complications, including $\mathrm{AD}$, vascular dementia, and cognitive decline. Numerous clinical studies have highlighted the potential of TCMs in the treatment of DM-related cognitive decline. Despite the fact that most of these trials have shown positive outcomes, significant methodological issues such as small sample sizes and poor randomization exist in many of these studies. Therefore, more rigorously designed randomized controlled trials are required to further validate these findings. Finally, most of the preclinical studies assessing the effects of CHMs on DM-mediated cognitive dysfunction were performed using single herbs or isolated active ingredients. Given that the traditional use of CHMs is based on complex formulation, more research on the synergic effects of herbal combinations is required for a more comprehensive understanding of the mechanisms underlying their effect on the diseases.

\section{Conflict of Interests}

The authors declare that there is no conflict of interests regarding the publication of this paper.

\section{References}

[1] V. Darsalia, U. Heldmann, O. Lindvall, and Z. Kokaia, "Strokeinduced neurogenesis in aged brain," Stroke, vol. 36, no. 8, pp. 1790-1795, 2005.

[2] D. R. Whiting, L. Guariguata, C. Weil, and J. Shaw, "IDF diabetes atlas: global estimates of the prevalence of diabetes for 2011 and 2030," Diabetes Research and Clinical Practice, vol. 94, no. 3, pp. 311-321, 2011.

[3] Z. Arvanitakis, R. S. Wilson, J. L. Bienias, D. A. Evans, and D. A. Bennett, "Diabetes mellitus and risk of Alzheimer disease and decline in cognitive function," Archives of Neurology, vol. 61, no. 5, pp. 661-666, 2004.

[4] M. M. B. Breteler, "Vascular involvement in cognitive decline and dementia. Epidemiologic evidence from the Rotterdam study and the Rotterdam scan study," Annals of the New York Academy of Sciences, vol. 903, pp. 457-465, 2000.

[5] M. W. J. Strachan, R. M. Reynolds, R. E. Marioni, and J. F. Price, "Cognitive function, dementia and type 2 diabetes mellitus in the elderly," Nature Reviews Endocrinology, vol. 7, no. 2, pp. 108$114,2011$.

[6] G. Cheng, C. Huang, H. Deng, and H. Wang, "Diabetes as a risk factor for dementia and mild cognitive impairment: a metaanalysis of longitudinal studies," Internal Medicine Journal, vol. 42, no. 5, pp. 484-491, 2012.

[7] G. J. Biessels, S. Staekenborg, E. Brunner, C. Brayne, and P. Scheltens, "Risk of dementia in diabetes mellitus: a systematic review," The Lancet Neurology, vol. 5, no. 1, pp. 64-74, 2006.

[8] F.-P. Lu, K.-P. Lin, and H.-K. Kuo, "Diabetes and the risk of multi-system aging phenotypes: a systematic review and metaanalysis," PLoS ONE, vol. 4, no. 1, Article ID e4144, 2009.

[9] G. J. Biessels, A. Koffeman, and P. Scheltens, "Diabetes and cognitive impairment: clinical diagnosis and brain imaging in patients attending a memory clinic," Journal of Neurology, vol. 253, no. 4, pp. 477-482, 2006.

[10] A. D. Korczyn, "Mixed dementia-the most common cause of dementia," Annals of the New York Academy of Sciences, vol. 977, pp. 129-134, 2002.

[11] P. B. Gorelick, A. Scuteri, S. E. Black et al., "Vascular contributions to cognitive impairment and dementia: a statement for healthcare professionals from the American Heart Association/American Stroke Association," Stroke, vol. 42, no. 9, pp. 2672-2713, 2011.

[12] J. B. Toledo, S. E. Arnold, K. Raible et al., "Contribution of cerebrovascular disease in autopsy confirmed neurodegenerative disease cases in the National Alzheimer's Coordinating Centre," Brain, vol. 136, no. 9, pp. 2697-2706, 2013.

[13] A. M. Jacobson, G. Musen, C. M. Ryan et al., "Long-term effect of diabetes and its treatment on cognitive function," The New England Journal of Medicine, vol. 356, no. 18, pp. 1842-1852, 2007.

[14] J. A. Luchsinger, W. Palmas, J. A. Teresi et al., "Improved diabetes control in the elderly delays global cognitive decline," Journal of Nutrition, Health \& Aging, vol. 15, no. 6, pp. 445-449, 2011.

[15] C. M. Ryan, T. M. Williams, D. N. Finegold, and T. J. Orchard, "Cognitive dysfunction in adults with Type 1 (insulindependent) diabetes mellitus of long duration: effects of recurrent hypoglycaemia and other chronic complications," Diabetologia, vol. 36, no. 4, pp. 329-334, 1993.

[16] L. J. Launer, M. E. Miller, J. D. Williamson et al., "Effects of intensive glucose lowering on brain structure and function in 
people with type 2 diabetes (ACCORD MIND): a randomised open-label substudy," The Lancet Neurology, vol. 10, no. 11, pp. 969-977, 2011.

[17] J. Li, J. Deng, W. Sheng, and Z. Zuo, "Metformin attenuates Alzheimer's disease-like neuropathology in obese, leptinresistant mice," Pharmacology Biochemistry and Behavior, vol. 101, no. 4, pp. 564-574, 2012.

[18] M. E. Risner, A. M. Saunders, J. F. B. Altman et al., "Efficacy of rosiglitazone in a genetically defined population with mild-tomoderate Alzheimer's disease," The Pharmacogenomics Journal, vol. 6, no. 4, pp. 246-254, 2006.

[19] W. L. Li, H. C. Zheng, J. Bukuru, and N. de Kimpe, "Natural medicines used in the traditional Chinese medical system for therapy of diabetes mellitus," Journal of Ethnopharmacology, vol. 92, no. 1, pp. 1-21, 2004.

[20] X. Xu, L. Guo, and G. Tian, "Diabetes cognitive impairments and the effect of traditional Chinese herbs," Evidence-based Complementary and Alternative Medicine, vol. 2013, Article ID 649396, 10 pages, 2013.

[21] T. Cukierman-Yaffe, H. C. Gerstein, J. D. Williamson et al., "Relationship between baseline glycemic control and cognitive function in individuals with type 2 diabetes and other cardiovascular risk factors: The Action to Control Cardiovascular Risk in Diabetes-Memory in Diabetes (ACCORD-MIND) Trial," Diabetes Care, vol. 32, no. 8, pp. 221-226, 2009.

[22] A. Fontbonne, C. Berr, P. Ducimetiere, and A. Alperovitch, "Changes in cognitive abilities over a 4-year period are unfavorably affected in elderly diabetic subjects: results of the epidemiology of vascular aging study," Diabetes Care, vol. 24, no. 2, pp. 366-370, 2001.

[23] T. Cukierman, H. C. Gerstein, and J. D. Williamson, "Cognitive decline and dementia in diabetes-systematic overview of prospective observational studies," Diabetologia, vol. 48, no. 12, pp. 2460-2469, 2005.

[24] A. M. A. Brands, G. J. Biessels, E. H. F. de Haan, L. J. Kappelle, and R. P. C. Kessels, "The effects of type 1 diabetes on cognitive performance: a meta-analysis," Diabetes Care, vol. 28, no. 3, pp. 726-735, 2005.

[25] F. Grodstein, J. Chen, R. S. Wilson, and J. E. Manson, “Type 2 diabetes and cognitive function in community-dwelling elderly women," Diabetes Care, vol. 24, no. 6, pp. 1060-1065, 2001.

[26] C. Messier, "Impact of impaired glucose tolerance and type 2 diabetes on cognitive aging," Neurobiology of Aging, vol. 26, no. 1, supplement, pp. 26-30, 2005.

[27] A. D. Mooradian, J. Li, and G. N. Shah, "Age-related changes in thyroid hormone responsive protein (THRP) expression in cerebral tissue of rats," Brain Research, vol. 793, no. 1-2, pp. 302304, 1998.

[28] E. J. Schoenle, D. Schoenle, L. Molinari, and R. H. Largo, "Impaired intellectual development in children with type I diabetes: association with HbAlc, age at diagnosis and sex," Diabetologia, vol. 45, no. 1, pp. 108-114, 2002.

[29] A. M. Wessels, S. A. R. B. Rombouts, P. L. Remijnse et al., "Cognitive performance in type 1 diabetes patients is associated with cerebral white matter volume," Diabetologia, vol. 50, no. 8, pp. 1763-1769, 2007.

[30] C. Ruis, G. J. Biessels, K. J. Gorter, M. Van Den Donk, L. J. Kappelle, and G. E. H. M. Rutten, "Cognition in the early stage of type 2 diabetes," Diabetes Care, vol. 32, no. 7, pp. 1261-1265, 2009.

[31] E. A. Northam, P. J. Anderson, G. A. Werther, G. L. Warne, and D. Andrewes, "Predictors of change in the neuropsychological profiles of children with type 1 diabetes 2 years after disease onset," Diabetes Care, vol. 22, no. 9, pp. 1438-1444, 1999.

[32] P. K. Crane, R. Walker, R. A. Hubbard et al., "Glucose levels and risk of dementia," The New England Journal of Medicine, vol. 369, no. 6, pp. 540-548, 2013.

[33] L. Kerti, A. V. Witte, A. Winkler, U. Grittner, D. Rujescu, and A. Flöel, "Higher glucose levels associated with lower memory and reduced hippocampal microstructure," Neurology, vol. 81, no. 20, pp. 1746-1752, 2013.

[34] R. McKelvey, H. Bergman, J. Stern, C. Rush, G. Zahirney, and H. Chertkow, "Lack of prognostic significance of SPECT abnormalities in non-demented elderly subjects with memory loss," Le Journal Canadien des Sciences Neurologiques, vol. 26, no. 1, pp. 23-28, 1999.

[35] P. J. Modrego, N. Fayed, and M. A. Pina, "Conversion from mild cognitive impairment to probable Alzheimer's disease predicted by brain magnetic resonance spectroscopy," American Journal of Psychiatry, vol. 162, no. 4, pp. 667-675, 2005.

[36] J. C. Morris, M. Storandt, J. P. Miller et al., "Mild cognitive impairment represents early-stage Alzheimer disease," Archives of Neurology, vol. 58, no. 3, pp. 397-405, 2001.

[37] S. Artero, M. L. Ancelin, F. Portet et al., "Risk profiles for mild cognitive impairment and progression to dementia are gender specific," Journal of Neurology, Neurosurgery and Psychiatry, vol. 79, no. 9, pp. 979-984, 2008.

[38] W. Xu, B. Caracciolo, H.-X. Wang et al., "Accelerated progression from mild cognitive impairment to dementia in people with diabetes," Diabetes, vol. 59, no. 11, pp. 2928-2935, 2010.

[39] Y.-C. Chen, Y. Jiao, Y. Cui et al., "Aberrant brain functional connectivity related to insulin resistance in type 2 diabetes: a resting-state fmri study," Diabetes Care, vol. 37, no. 6, pp. 16891696, 2014.

[40] N. García-Casares, R. E. Jorge, J. A. García-Arnés et al., "Cognitive dysfunctions in middle-aged type 2 diabetic patients and neuroimaging correlations: a cross-sectional study," Journal of Alzheimer's Disease, vol. 42, no. 4, pp. 1337-1346, 2014.

[41] W. Xia, S. Wang, Z. Sun et al., "Altered baseline brain activity in type 2 diabetes: a resting-state fMRI study," Psychoneuroendocrinology, vol. 38, no. 11, pp. 2493-2501, 2013.

[42] C. X. Wang, K. L. Fu, H. J. Liu, F. Xing, S. Zhang, and P. A. Valdes-Sosa, "Spontaneous brain activity in type 2 diabetics revealed by amplitude of low-frequency fluctuations and its association with diabetic vascular disease: a resting-state FMRI study," PLoS ONE, vol. 9, no. 10, Article ID e108883, 2014.

[43] H. Zhou, W. Lu, Y. Shi et al., "Impairments in cognition and resting-state connectivity of the hippocampus in elderly subjects with type 2 diabetes," Neuroscience Letters, vol. 473, no. 1, pp. 5-10, 2010.

[44] L. G. Exalto, R. A. Whitmer, L. J. Kappele, and G. J. Biessels, "An update on type 2 diabetes, vascular dementia and Alzheimer's disease," Experimental Gerontology, vol. 47, no. 11, pp. 858-864, 2012.

[45] Y. D. Reijmer, E. van den Berg, C. Ruis, L. J. Kappelle, and G. J. Biessels, "Cognitive dysfunction in patients with type 2 diabetes," Diabetes/Metabolism Research and Reviews, vol. 26, no. 7, pp. 507-519, 2010.

[46] D. G. Bruce, W. A. Davis, G. P. Casey et al., "Predictors of cognitive impairment and dementia in older people with diabetes," Diabetologia, vol. 51, no. 2, pp. 241-248, 2008.

[47] R. Peila, B. L. Rodriguez, and L. J. Launer, "Type 2 diabetes, APOE gene, and the risk for dementia and related pathologies: 
the Honolulu-Asia Aging Study," Diabetes, vol. 51, no. 4, pp. 1256-1262, 2002.

[48] S. C. M. Croxson and C. Jagger, "Diabetes and cognitive impairment: a community-based study of elderly subjects," Age and Ageing, vol. 24, no. 5, pp. 421-424, 1995.

[49] L. B. Hassing, M. D. Grant, S. M. Hofer et al., "Type 2 diabetes mellitus contributes to cognitive decline in old age: a longitudinal population-based study," Journal of the International Neuropsychological Society, vol. 10, no. 4, pp. 599-607, 2004.

[50] R. Katzman, D. Kang, and R. Thomas, "Interaction of apolipoprotein E $\varepsilon 4$ with other genetic and non-genetic risk factors in late onset Alzheimer disease: problems facing the investigator," Neurochemical Research, vol. 23, no. 3, pp. 369376, 1998.

[51] N. M. Parikh, R. O. Morgan, M. E. Kunik et al., "Risk factors for dementia in patients over 65 with diabetes," International Journal of Geriatric Psychiatry, vol. 26, no. 7, pp. 749-757, 2011.

[52] W. H. Gispen and G.-J. Biessels, "Cognition and synaptic plasticity in diabetes mellitus," Trends in Neurosciences, vol. 23, no. 11, pp. 542-549, 2000.

[53] S. Ahtiluoto, T. Polvikoski, M. Peltonen et al., "Diabetes, Alzheimer disease, and vascular dementia: a population-based neuropathologic study," Neurology, vol. 75, no. 13, pp. 1195-1202, 2010.

[54] J. A. Sonnen, E. B. Larson, K. Brickell et al., "Different patterns of cerebral injury in dementia with or without diabetes," Archives of Neurology, vol. 66, no. 3, pp. 315-322, 2009.

[55] J. C. de la Torre, "Detection, prevention, and pre-clinical treatment of Alzheimer's disease," Journal of Alzheimer's Disease, vol. 42, supplement 4, pp. S327-S328, 2014.

[56] K. J. Kwon, E. J. Lee, M. K. Kim et al., "Diabetes augments cognitive dysfunction in chronic cerebral hypoperfusion by increasing neuronal cell death: implication of cilostazol for diabetes mellitus-induced dementia," Neurobiology of Disease, vol. 73, pp. 12-23, 2015.

[57] P. K. Elias, M. F. Elias, R. B. D’Agostino et al., "NIDDM and blood pressure as risk factors for poor cognitive performance: the Framingham Study," Diabetes Care, vol. 20, no. 9, pp. 13881395, 1997.

[58] E. van den Berg, Y. D. Reijmer, J. de Bresser, R. P. C. Kessels, L. J. Kappelle, and G. J. Biessels, "A 4 year follow-up study of cognitive functioning in patients with type 2 diabetes mellitus," Diabetologia, vol. 53, no. 1, pp. 58-65, 2010.

[59] S. J. Hamilton and G. F. Watts, "Atherogenic dyslipidemia and combination pharmacotherapy in diabetes: recent clinical trials," The Review of Diabetic Studies, vol. 10, no. 2-3, pp. 191203, 2013.

[60] D. C. Chan, P. H. R. Barrett, and G. F. Watts, "The metabolic and pharmacologic bases for treating atherogenic dyslipidaemia," Best Practice \& Research: Clinical Endocrinology \& Metabolism, vol. 28, no. 3, pp. 369-385, 2014.

[61] R. P. Kloppenborg, E. van den Berg, L. J. Kappelle, and G. J. Biessels, "Diabetes and other vascular risk factors for dementia: which factor matters most? A systematic review," European Journal of Pharmacology, vol. 585, no. 1, pp. 97-108, 2008.

[62] G. Rodriguez, F. Nobili, M. A. Celestino et al., "Regional cerebral blood flow and cerebrovascular reactivity in IDDM," Diabetes Care, vol. 16, no. 2, pp. 462-468, 1993.

[63] M. T. Schram, N. Chaturvedi, C. G. Schalkwijk, J. H. Fuller, and C. D. A. Stehouwer, "Markers of inflammation are crosssectionally associated with microvascular complications and cardiovascular disease in type 1 diabetes-the EURODIAB Prospective Complications Study," Diabetologia, vol. 48, no. 2, pp. 370-378, 2005.

[64] M. Suzuki, M. Saito, T. Nagai, H. Saeki, and Y. Kazatani, "Systemic versus coronary levels of inflammation in acute coronary syndromes," Angiology, vol. 57, no. 4, pp. 459-463, 2006.

[65] M. Yngen, C. G. Östenson, H. Hu, N. Li, P. Hjemdahl, and N. H. Wallén, "Enhanced P-selectin expression and increased soluble CD40 Ligand in patients with type 1 diabetes mellitus and microangiopathy: evidence for platelet hyperactivity and chronic inflammation," Diabetologia, vol. 47, no. 3, pp. 537-540, 2004.

[66] G. J. Biessels, E. J. Stevens, S. J. Mahmood, W. H. Gispen, and D. R. Tomlinson, "Insulin partially reverses deficits in peripheral nerve blood flow and conduction in experimental diabetes," Journal of the Neurological Sciences, vol. 140, no. 1-2, pp. 12-20, 1996.

[67] D. R. Thal, L. T. Grinberg, and J. Attems, "Vascular dementia: different forms of vessel disorders contribute to the development of dementia in the elderly brain," Experimental Gerontology, vol. 47, no. 11, pp. 816-824, 2012.

[68] S. M. Gold, I. Dziobek, V. Sweat et al., "Hippocampal damage and memory impairments as possible early brain complications of type 2 diabetes," Diabetologia, vol. 50, no. 4, pp. 711-719, 2007.

[69] A. M. Kanaya, E. Barrett-Connor, G. Gildengorin, and K. Yaffe, "Change in cognitive function by glucose tolerance status in older adults: a 4-year prospective study of the Rancho Bernardo Study cohort," Archives of Internal Medicine, vol. 164, no. 12, pp. 1327-1333, 2004.

[70] M. Vanhanen and H. Soininen, "Glucose intolerance, cognitive impairment and Alzheimer's disease," Current Opinion in Neurology, vol. 11, no. 6, pp. 673-677, 1998.

[71] K. Yaffe, T. Blackwell, R. A. Whitmer, K. Krueger, and E. BarrettConnor, "Glycosylated hemoglobin level and development of mild cognitive impairment or dementia in older women," Journal of Nutrition, Health \& Aging, vol. 10, no. 4, pp. 292-295, 2006.

[72] G. M. Reaven, L. W. Thompson, D. Nahum, and E. Haskins, "Relationship between hyperglycemia and cognitive function in older NIDDM patients," Diabetes Care, vol. 13, no. 1, pp. 16-21, 1990.

[73] E. Wright Jr., J. L. Scism-Bacon, and L. C. Glass, "Oxidative stress in type 2 diabetes: the role of fasting and postprandial glycaemia," International Journal of Clinical Practice, vol. 60, no. 3, pp. 308-314, 2006.

[74] C. Toth, V. Brussee, J. A. Martinez, D. McDonald, F. A. Cunningham, and D. W. Zochodne, "Rescue and regeneration of injured peripheral nerve axons by intrathecal insulin," Neuroscience, vol. 139, no. 2, pp. 429-449, 2006.

[75] X. Gironès, A. Guimerà, C.-Z. Cruz-Sánchez et al., "Nعcarboxymethyllysine in brain aging, diabetes mellitus, and Alzheimer's disease," Free Radical Biology \& Medicine, vol. 36, no. 10, pp. 1241-1247, 2004.

[76] F. K. Ahmad, Z. He, and G. L. King, "Molecular targets of diabetic cardiovascular complications," Current Drug Targets, vol. 6, no. 4, pp. 487-494, 2005.

[77] T. Valente, A. Gella, X. Fernàndez-Busquets, M. Unzeta, and N. Durany, "Immunohistochemical analysis of human brain suggests pathological synergism of Alzheimer's disease and diabetes mellitus," Neurobiology of Disease, vol. 37, no. 1, pp. 6776, 2010. 
[78] D. Comin, L. Gazarini, J. N. Zanoni, H. Milani, and R. M. W. de Oliveira, "Vitamin E improves learning performance and changes the expression of nitric oxide-producing neurons in the brains of diabetic rats," Behavioural Brain Research, vol. 210, no. 1, pp. 38-45, 2010.

[79] K. Fukui, N. O. Omoi, T. Hayasaka et al., "Cognitive impairment of rats caused by oxidative stress and aging, and its prevention by vitamin E," Annals of the New York Academy of Sciences, vol. 959, pp. 275-284, 2002.

[80] M. Brownlee, "The pathobiology of diabetic complications: a unifying mechanism," Diabetes, vol. 54, no. 6, pp. 1615-1625, 2005.

[81] R. N. Auer, "Hypoglycemic brain damage," Metabolic Brain Disease, vol. 19, no. 3-4, pp. 169-175, 2004.

[82] A. W. Patrick, R. F. Jeffrey, A. Collier, B. F. Clarke, and M. R. Lee, "Relationship between urinary excretion of sodium and dopamine in Type 1 diabetic patients with and without microalbuminuria," Diabetic Medicine, vol. 7, no. 1, pp. 53-56, 1990.

[83] E. C. McNay and V. E. Cotero, "Mini-review: impact of recurrent hypoglycemia on cognitive and brain function," Physiology \& Behavior, vol. 100, no. 3, pp. 234-238, 2010.

[84] R. A. Whitmer, A. J. Karter, K. Yaffe, C. P. Quesenberry Jr., and J. V. Selby, "Hypoglycemic episodes and risk of dementia in older patients with type 2 diabetes mellitus," Journal of the American Medical Association, vol. 301, no. 15, pp. 1565-1572, 2009.

[85] D. G. Bruce, W. A. Davis, G. P. Casey et al., "Severe hypoglycaemia and cognitive impairment in older patients with diabetes: the Fremantle Diabetes Study," Diabetologia, vol. 52, no. 9, pp. 1808-1815, 2009.

[86] R. E. Warren and B. M. Frier, "Hypoglycaemia and cognitive function," Diabetes, Obesity \& Metabolism, vol. 7, no. 5, pp. 493503, 2005.

[87] T. Hershey, S. Craft, N. Bhargava, and N. H. White, "Memory and insulin dependent diabetes mellitus (IDDM): effects of childhood onset and severe hypoglycemia," Journal of the International Neuropsychological Society, vol. 3, no. 6, pp. 509520, 1997.

[88] W. A. Banks, M. J. During, and M. L. Niehoff, "Brain uptake of the glucagon-like peptide-1 antagonist exendin(9-39) after intranasal administration," The Journal of Pharmacology and Experimental Therapeutics, vol. 309, no. 2, pp. 469-475, 2004.

[89] S. C. Woods, R. J. Seeley, D. G. Baskin, and M. W. Schwartz, "Insulin and the blood-brain barrier," Current Pharmaceutical Design, vol. 9, no. 10, pp. 795-800, 2003.

[90] E. Steen, B. M. Terry, E. J. Rivera et al., "Impaired insulin and insulin-like growth factor expression and signaling mechanisms in Alzheimer's disease-is this type 3 diabetes?" Journal of Alzheimer's Disease, vol. 7, no. 1, pp. 63-80, 2005.

[91] C. A. Bondy and C. M. Cheng, "Signaling by insulin-like growth factor 1 in brain," European Journal of Pharmacology, vol. 490, no. 1-3, pp. 25-31, 2004.

[92] K. Gerozissis, "Brain insulin and feeding: a bi-directional communication," European Journal of Pharmacology, vol. 490, no. 1-3, pp. 59-70, 2004.

[93] W.-Q. Zhao and D. L. Alkon, "Role of insulin and insulin receptor in learning and memory," Molecular and Cellular Endocrinology, vol. 177, no. 1-2, pp. 125-134, 2001.

[94] L. Frölich, D. Blum-Degen, H.-G. Bernstein et al., "Brain insulin and insulin receptors in aging and sporadic Alzheimer's disease," Journal of Neural Transmission, vol. 105, no. 4-5, pp. 423-438, 1998.
[95] S. Kalmijn, J. A. M. J. L. Janssen, H. A. P. Pols, S. W. J. Lamberts, and M. M. B. Breteler, "A prospective study on circulating insulin-like growth factor I (IGF-I), IGF-binding proteins, and cognitive function in the elderly," The Journal of Clinical Endocrinology \& Metabolism, vol. 85, no. 12, pp. 4551$4555,2000$.

[96] J. Kuusisto, K. Koivisto, L. Mykkänen et al., "Association between features of the insulin resistance syndrome and Alzheimer's disease independently of apolipoprotein E4 phenotype: cross sectional population based study," The British Medical Journal, vol. 315, no. 7115, pp. 1045-1049, 1997.

[97] W. Farris, S. Mansourian, Y. Chang et al., "Insulin-degrading enzyme regulates the levels of insulin, amyloid $\beta$-protein, and the $\beta$-amyloid precursor protein intracellular domain in vivo," Proceedings of the National Academy of Sciences of the United States of America, vol. 100, no. 7, pp. 4162-4167, 2003.

[98] W. Q. Qiu, D. M. Walsh, Z. Ye et al., "Insulin-degrading enzyme regulates extracellular levels of amyloid $\beta$-protein by degradation," The Journal of Biological Chemistry, vol. 273, no. 49, pp. 32730-32738, 1998.

[99] R. V. Bhat, J. Shanley, M. P. Correll et al., "Regulation and localization of tyrosine 216 phosphorylation of glycogen synthase kinase- $3 \beta$ in cellular and animal models of neuronal degeneration," Proceedings of the National Academy of Sciences of the United States of America, vol. 97, no. 20, pp. 11074-11079, 2000 .

[100] C. J. Phiel, C. A. Wilson, V. M.-Y. Lee, and P. S. Klein, "GSK- $3 \alpha$ regulates production of Alzheimer's disease amyloid$\beta$ peptides," Nature, vol. 423, no. 6938, pp. 435-439, 2003.

[101] A. Badawi, A. Klip, P. Haddad et al., “Type 2 diabetes mellitus and inflammation: prospects for biomarkers of risk and nutritional intervention," Diabetes, Metabolic Syndrome and Obesity: Targets and Therapy, vol. 4, pp. 173-186, 2010.

[102] J. C. Pickup and M. A. Crook, "Is type II diabetes mellitus a disease of the innate immune system?" Diabetologia, vol. 41, no. 10, pp. 1241-1248, 1998.

[103] G. L. King, "The role of inflammatory cytokines in diabetes and its complications," Journal of Periodontology, vol. 79, no. 8, pp. $1527-1534,2008$

[104] H. Akiyama, T. Arai, H. Kondo, E. Tanno, C. Haga, and K. Ikeda, "Cell mediators of inflammation in the Alzheimer disease brain," Alzheimer Disease \& Associated Disorders, vol. 14, no. 1, pp. S47-S53, 2000.

[105] S. T. Ferreira, J. R. Clarke, T. R. Bomfim, and F. G. de Felice, "Inflammation, defective insulin signaling, and neuronal dysfunction in Alzheimer's disease," Alzheimer's and Dementia, vol. 10, no. 1, pp. S76-S83, 2014.

[106] N. K. Acharya, E. C. Levin, P. M. Clifford et al., "Diabetes and hypercholesterolemia increase blood-brain barrier permeability and brain amyloid deposition: beneficial effects of the LpPLA2 inhibitor darapladib," Journal of Alzheimer's Disease, vol. 35, no. 1, pp. 179-198, 2013.

[107] A. J. Farrall and J. M. Wardlaw, "Blood-brain barrier: ageing and microvascular disease-systematic review and meta-analysis," Neurobiology of Aging, vol. 30, no. 3, pp. 337-352, 2009.

[108] R. D. Bell and B. V. Zlokovic, "Neurovascular mechanisms and blood-brain barrier disorder in Alzheimer's disease," Acta Neuropathologica, vol. 118, no. 1, pp. 103-113, 2009.

[109] R. L. Ownby, "Neuroinflammation and cognitive aging," Current Psychiatry Reports, vol. 12, no. 1, pp. 39-45, 2010. 
[110] S. W. Pimplikar, "Neuroinflammation in Alzheimer's disease: from pathogenesis to a therapeutic target," Journal of Clinical Immunology, vol. 34, supplement 1, pp. S64-S69, 2014.

[111] T. R. Bomfim, L. Forny-Germano, L. B. Sathler et al., "An anti-diabetes agent protects the mouse brain from defective insulin signaling caused by Alzheimer's disease-associated $\mathrm{A} \beta$ oligomers," Journal of Clinical Investigation, vol. 122, no. 4, pp. 1339-1353, 2012.

[112] G. S. Hotamisligil, R. S. Johnson, R. J. Distel, R. Ellis, V. E. Papaioannou, and B. M. Spiegelman, "Uncoupling of obesity from insulin resistance through a targeted mutation in $a P 2$, the adipocyte fatty acid binding protein," Science, vol. 274, no. 5291, pp. 1377-1379, 1996.

[113] M. Milanski, G. Degasperi, A. Coope et al., "Saturated fatty acids produce an inflammatory response predominantly through the activation of TLR4 signaling in hypothalamus: implications for the pathogenesis of obesity," The Journal of Neuroscience, vol. 29, no. 2, pp. 359-370, 2009.

[114] S. W. Seto, Y. W. Kwan, and S. M. Ngai, "Modulatory effect of interleukin- $1 \beta$ on rat isolated basilar artery contraction," European Journal of Pharmacology, vol. 531, no. 1-3, pp. 238245, 2006.

[115] B. Lin, N. Koibuchi, Y. Hasegawa et al., "Glycemic control with empagliflozin, a novel selective SGLT2 inhibitor, ameliorates cardiovascular injury and cognitive dysfunction in obese and type 2 diabetic mice," Cardiovascular Diabetology, vol. 13, no. 1, article 148, 2014.

[116] S. Heller, P. Kozlovski, and P. Kurtzhals, "Insulin's 85th anniversary-an enduring medical miracle," Diabetes Research and Clinical Practice, vol. 78, no. 2, pp. 149-158, 2007.

[117] E. R. Seaquist, J. Anderson, B. Childs et al., "Hypoglycemia and diabetes: a report of aworkgroup of the American diabetes association and the endocrine society," Diabetes Care, vol. 36, no. 5, pp. 1384-1395, 2013.

[118] G. Languren, T. Montiel, A. Julio-Amilpas, and L. Massieu, "Neuronal damage and cognitive impairment associated with hypoglycemia: an integrated view," Neurochemistry International, vol. 63, no. 4, pp. 331-343, 2013.

[119] B. Y. Dai, "Present advance in therapeutical mechanism of diabetes in traditional Chinese medicial system," Chinese Journal of Information on Traditional Chinese Medicine, vol. 7, pp. 23-24, 2000.

[120] K. Y. Zhu, "A discuss on symptoms and therapies of diabetes in traditional Chinese medical system," Shanghai Journal of Traditional Chinese Medicine, vol. 6, p. 6, 1982.

[121] J. Guo, H. Chen, J. Song, J. Wang, L. Zhao, and X. Tong, "Syndrome differentiation of diabetes by the traditional Chinese medicine according to evidence-based medicine and expert consensus opinion," Evidence-Based Complementary and Alternative Medicine, vol. 2014, Article ID 492193, 7 pages, 2014.

[122] H.-N. Wang, "Characteristics and difficulties in clinical trials of new traditional Chinese drugs," Chinese Journal of Integrated Traditional and Western Medicine, vol. 27, no. 7, pp. 650-652, 2007.

[123] X. Qin, Y. Liu, Y. Wu et al., "A meta-analysis of Chinese herbal medicines for vascular dementia," Neural Regeneration Research, vol. 8, no. 18, pp. 1685-1692, 2013.

[124] B. L. Sun and C. K. Chiang, "Effect of danhong injection on apnea hypopnea syndrome patients with Type 2 diabetes," Chinese Journal of Clinical Rational Drug Use, vol. 7, pp. 121-122, 2014.
[125] H. P. Zhang, H. Z. Li, and T. S. Lau, "Effect of astragalus and ligustrazine injection on short-term memory and brain evoked potentials of diabetic patients with decreased brain function," Chinese Journal of Gerontology, vol. 30, pp. 888-890, 2010.

[126] F. Zou, X.-Q. Mao, N. Wang, J. Liu, and J.-P. Ou-Yang, "Astragalus polysaccharides alleviates glucose toxicity and restores glucose homeostasis in diabetic states via activation of AMPK," Acta Pharmacologica Sinica, vol. 30, no. 12, pp. 1607-1615, 2009.

[127] W. Zhang, L. Zheng, Z. Zhang, and C.-X. Hai, "Protective effect of a water-soluble polysaccharide from Salvia miltiorrhiza Bunge on insulin resistance in rats," Carbohydrate Polymers, vol. 89, no. 3, pp. 890-898, 2012.

[128] S. Qian, S. Wang, P. Fan, D. Huo, L. Dai, and Q. Qian, "Effect of Salvia miltiorrhiza hydrophilic extract on the endothelial biomarkers in diabetic patients with chronic artery disease," Phytotherapy Research, vol. 26, no. 10, pp. 1575-1578, 2012.

[129] H. Lee, M. Kim, S. Shik Shin, and M. Yoon, "Ginseng treatment reverses obesity and related disorders by inhibiting angiogenesis in female db/db mice," Journal of Ethnopharmacology, vol. 155, no. 2, pp. 1342-1352, 2014.

[130] E.-Y. Park, H.-J. Kim, Y.-K. Kim et al., "Increase in insulin secretion induced by panax ginseng berry extracts contributes to the amelioration of hyperglycemia in streptozotocininduced diabetic mice," Journal of Ginseng Research, vol. 36, no. 2, pp. 153-160, 2012.

[131] M. S. Chang, M. S. Oh, D. R. Kim et al., "Effects of Okchun-San, a herbal formulation, on blood glucose levels and body weight in a model of Type 2 diabetes," Journal of Ethnopharmacology, vol. 103, no. 3, pp. 491-495, 2006.

[132] J.-H. Hsu, Y.-C. Wu, I.-M. Liu, and J.-T. Cheng, "Dioscorea as the principal herb of Die-Huang-Wan, a widely used herbal mixture in China, for improvement of insulin resistance in fructose-rich chow-fed rats," Journal of Ethnopharmacology, vol. 112, no. 3, pp. 577-584, 2007.

[133] S. W. Seto, T. Y. Lam, H. L. Tam et al., "Novel hypoglycemic effects of Ganoderma lucidum water-extract in obese/diabetic $(+\mathrm{db} /+\mathrm{db})$ mice," Phytomedicine, vol. 16, no. 5, pp. 426-436, 2009.

[134] S. H. Kim and S. Y. Choung, "Antihyperglycemic and antihyperlipidemic action of Cinnamomi Cassiae (Cinnamon bark) extract in $\mathrm{C} 57 \mathrm{BL} / \mathrm{Ks} \mathrm{db} / \mathrm{db}$ mice," Archives of Pharmacal Research, vol. 33, no. 2, pp. 325-333, 2010.

[135] S. H. Kim, S. H. Hyun, and S. Y. Choung, "Antioxidative effects of Cinnamomi cassiae and Rhodiola rosea extracts in liver of diabetic mice," BioFactors, vol. 26, no. 3, pp. 209-219, 2006.

[136] D. Y. Kwon, Y. S. Kim, S. Y. Ryu et al., "Platyconic acid, a saponin from Platycodi radix, improves glucose homeostasis by enhancing insulin sensitivity in vitro and in vivo," European Journal of Nutrition, vol. 51, no. 5, pp. 529-540, 2012.

[137] Q.-H. Yang, Y. Liang, Q. Xu, Y. Zhang, L. Xiao, and L.-Y. Si, "Protective effect of tetramethylpyrazine isolated from Ligusticum chuanxiong on nephropathy in rats with streptozotocininduced diabetes," Phytomedicine, vol. 18, no. 13, pp. 1148-1152, 2011.

[138] D. Gao, M. Zhao, X. Qi et al., "Hypoglycemic effect of Gynostemma pentaphyllum saponins by enhancing the Nrf2 signaling pathway in STZ-inducing diabetic rats," Archives of Pharmacal Research, 2014.

[139] W. Qiao, C. Zhao, N. Qin, H. Y. Zhai, and H. Q. Duan, "Identification of trans-tiliroside as active principle with antihyperglycemic, anti-hyperlipidemic and antioxidant effects 
from Potentilla chinesis," Journal of Ethnopharmacology, vol. 135, no. 2, pp. 515-521, 2011.

[140] H. Nakamura, T. Ishigami, Y. Kawase et al., "Effects of acupuncture stimulation on blood glucose concentration in the Otsuka Long-Evans Tokushima Fatty (OLETF) rat, an animal model for type-2 diabetes mellitus," Medical Science Monitor Basic Research, vol. 20, pp. 70-75, 2014.

[141] S.-L. Chang, Y.-C. Lee, T.-M. Li et al., "Electroacupuncture at the Zusanli (ST-36) acupoint induces a hypoglycemic effect by stimulating the cholinergic nerve in a rat model of streptozotocine-induced insulin-dependent diabetes mellitus," Evidence-based Complementary and Alternative Medicine, vol. 2011, Article ID 650263, 6 pages, 2011.

[142] S. Choi, G.-J. Lee, S.-J. Chae et al., "Potential neuroprotective effects of acupuncture stimulation on diabetes mellitus in a global ischemic rat model," Physiological Measurement, vol. 31, no. 5, pp. 633-647, 2010.

[143] M. T. Cabioglu and N. Ergene, "Changes in levels of serum insulin, C-peptide and glucose after electroacupuncture and diet therapy in obese women," The American journal of Chinese medicine, vol. 34, no. 3, pp. 367-376, 2006.

[144] S. Ahn and R. Song, "Effects of tai chi exercise on glucose control, neuropathy scores, balance, and quality of life in patients with type 2 diabetes and neuropathy," Journal of Alternative and Complementary Medicine, vol. 18, no. 12, pp. 1172-1178, 2012.

[145] X. Liu, Y. D. Miller, N. W. Burton, J.-H. Chang, and W. J. Brown, "The effect of Tai Chi on health-related quality of life in people with elevated blood glucose or diabetes: a randomized controlled trial," Quality of Life Research, vol. 22, no. 7, pp. 17831786, 2013.

[146] R. Song, S. Ahn, B. L. Roberts, E. O. Lee, and Y. H. Ahn, "Adhering to a t'ai chi program to improve glucose control and quality of life for individuals with type 2 diabetes," Journal of Alternative and Complementary Medicine, vol. 15, no. 6, pp. 627632, 2009.

[147] Y. Zhang and F. H. Fu, "Effects of 14-week Tai Ji quan exercise on metabolic control in women with type 2 diabetes," The American Journal of Chinese Medicine, vol. 36, no. 4, pp. 647-654, 2008.

[148] S.-H. Yeh, H. Chuang, L.-W. Lin et al., "Regular Tai Chi Chuan exercise improves $\mathrm{T}$ cell helper function of patients with type 2 diabetes mellitus with an increase in T-bet transcription factor and IL-12 production," British Journal of Sports Medicine, vol. 43, no. 11, pp. 845-850, 2009.

[149] J. Y. Lin, J. H. Liu, X. H. Liu, and D. F. Gu, "Effect of Fufang Danshen Diwan on the cognitive function of diabetic patients complicated with coronary heart disease," Chinese Journal of New Drugs, vol. 18, pp. 1213-1216, 2009.

[150] H. L. Li and M. M. Yeung, "Clinical study of Zhi Nao capsule on cognitive dysfunction in type 2 diabetes patients," in Proceedings of the 7th Scientific Conference of the Chinese Assocation of Integrated Medicine, pp. 146-150, 2011.

[151] W.-W. Li, H. Guo, H.-H. Li, L.-L. Wang, H. Fu, and X.M. Wang, "Integration of traditional Chinese medicines and western medicines for treating diabetes mellitus with coronary heart disease: a systematic review," The Journal of Alternative and Complementary Medicine, vol. 19, no. 6, pp. 492-500, 2013.

[152] Y. Zhang, "Effect of Nao Xin Tong on cognitive functions in stroke patients with diabetes," Guide of China Medicine, vol. 12, pp. 265-266, 2014.

[153] X. Y. Ding, "Combined therapy of alprostadil with Lao Xin Tong improves cognitive functions in diabetic patients," Zhejiang Clinical Medical Journal, vol. 13, article 1251, 2011.
[154] C. Huang, C. Tan, J. He, J. Deng, and Z. Wei, "Clincial observation on shengmai dingzhi decoction in treating diabetes and cerebral vascular dementia," Henan Traditional Chinese Medicine, vol. 29, pp. 1179-1181, 2009.

[155] X. D. Ji, "Clinical study on the effect if Bushen Quyu Yizhi decoction in treating diabetic cognitive dysfunction," Liaoning Journal of Traditional Chinese Medicine, vol. 37, p. 2371, 2010.

[156] S. Jin, J. Lang, X. Yang et al., "Clinical reserach on efficacy of bushen huoxue kaiqiao prescription in the treatment of 30 diabetes-induced vascular mild cognitive impairment cases," Modernization of Traditional Chinese Medicine and Materia Medica, vol. 15, pp. 1051-1054, 2013.

[157] J. Filshie, "The non-drug treatment of neuralgic and neuropathic pain of malignancy," Cancer Surveys, vol. 7, no. 1, pp. 161193, 1988.

[158] P. Chou, H. Chu, and J.-G. Lin, "Effects of electroacupuncture treatment on impaired cognition and quality of life in Taiwanese stroke patients," Journal of Alternative and Complementary Medicine, vol. 15, no. 10, pp. 1067-1073, 2009.

[159] Y.-X. Xu, G.-Z. Chen, J.-W. Zhang, and Z.-Z. Zhu, "Influence of electro-acupuncture on quality of life in patients with diabetic cognitive dysfunction," Chinese Journal of Clinical Rehabilitation, vol. 9, no. 48, pp. 53-55, 2005.

[160] Y. Xu and J. Zhang, "Influence of electroacupuncture on learning and memory ability in diabetic cognitive dysfunction patients," Acupuncture Reserach, vol. 31, pp. 232-238, 2006.

[161] E. Chan, C. Y.-K. Wong, C.-W. Wan et al., "Evaluation of antioxidant capacity of root of scutellaria baicalensis georgi, in comparison with roots of Polygonum multiflorum thunb and Panax ginseng CA meyer," The American Journal of Chinese Medicine, vol. 38, no. 4, pp. 815-827, 2010.

[162] M. Y. Lee, D. S. Choi, M. K. Lee et al., "Comparison of acarbose and voglibose in diabetes patients who are inadequately controlled with basal insulin treatment: randomized, parallel, open-label, active-controlled study," Journal of Korean Medical Science, vol. 29, no. 1, pp. 90-97, 2014.

[163] F. Nanjo, M. Mori, K. Goto, and Y. Hara, "Radical scavenging activity of tea catechins and their related compounds," Bioscience, Biotechnology and Biochemistry, vol. 63, no. 9, pp. 16211623, 1999.

[164] J. Yan, Y. Zhao, S. Suo, Y. Liu, and B. Zhao, "Green tea catechins ameliorate adipose insulin resistance by improving oxidative stress," Free Radical Biology \& Medicine, vol. 52, no. 9, pp. 16481657, 2012.

[165] K. Unno, F. Takabayashi, H. Yoshida et al., "Daily consumption of green tea catechin delays memory regression in aged mice," Biogerontology, vol. 8, no. 2, pp. 89-95, 2007.

[166] T. Baluchnejadmojarad and M. Roghani, "Chronic epigallocatechin-3-gallate ameliorates learning and memory deficits in diabetic rats via modulation of nitric oxide and oxidative stress," Behavioural Brain Research, vol. 224, no. 2, pp. 305-310, 2011.

[167] P. Bhutada, Y. Mundhada, K. Bansod et al., "Protection of cholinergic and antioxidant system contributes to the effect of berberine ameliorating memory dysfunction in rat model of streptozotocin-induced diabetes," Behavioural Brain Research, vol. 220, no. 1, pp. 30-41, 2011.

[168] Y.-W. Liu, X. Zhu, W. Li et al., "Ginsenoside Re attenuates diabetes-associated cognitive deficits in rats," Pharmacology Biochemistry and Behavior, vol. 101, no. 1, pp. 93-98, 2012.

[169] F. F. Y. Lam, J. H. K. Yeung, J. H. Y. Cheung, and P. M. Y. Or, "Pharmacological evidence for calcium channel inhibition by 
Danshen (Salvia miltiorrhiza) on rat isolated femoral artery," Journal of Cardiovascular Pharmacology, vol. 47, no. 1, pp. 139145, 2006.

[170] C. G. Shi, Y. S. Yang, H. Li et al., "Tanshinol protects hippocampus and attenuates vascular dementia development," Journal of Asian Natural Products Research, vol. 16, pp. 667-676, 2014.

[171] Y. Liu, L. Wang, X. Li, C. Lv, D. Feng, and Z. Luo, “Tanshinone IIA improves impaired nerve functions in experimental diabetic rats," Biochemical and Biophysical Research Communications, vol. 399, no. 1, pp. 49-54, 2010.

[172] A. Kuhad and K. Chopra, "Curcumin attenuates diabetic encephalopathy in rats: behavioral and biochemical evidences," European Journal of Pharmacology, vol. 576, no. 1-3, pp. 34-42, 2007.

[173] A. Kuhad, S. Sharma, and K. Chopra, "Lycopene attenuates thermal hyperalgesia in a diabetic mouse model of neuropathic pain," European Journal of Pain, vol. 12, no. 5, pp. 624-632, 2008.

[174] T. Wang, F. Fu, B. Han, L. Zhang, and X. Zhang, "Danshensu ameliorates the cognitive decline in streptozotocin-induced diabetic mice by attenuating advanced glycation end productmediated neuroinflammation," Journal of Neuroimmunology, vol. 245, no. 1-2, pp. 79-86, 2012.

[175] J.-P. Liu, L. Feng, M.-H. Zhang et al., "Neuroprotective effect of Liuwei Dihuang decoction on cognition deficits of diabetic encephalopathy in streptozotocin-induced diabetic rat," Journal of Ethnopharmacology, vol. 150, no. 1, pp. 371-381, 2013.

[176] J. Chen, L. Liang, L. Zhan et al., "ZiBuPiYin recipe protects $\mathrm{db} / \mathrm{db}$ mice from diabetes-associated cognitive decline through improving multiple pathological changes," PLoS ONE, vol. 9, no. 3, Article ID e91680, 2014. 


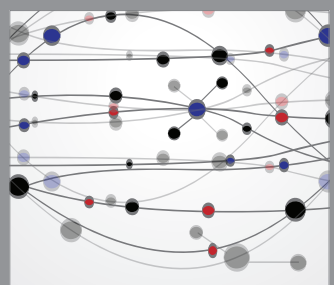

The Scientific World Journal
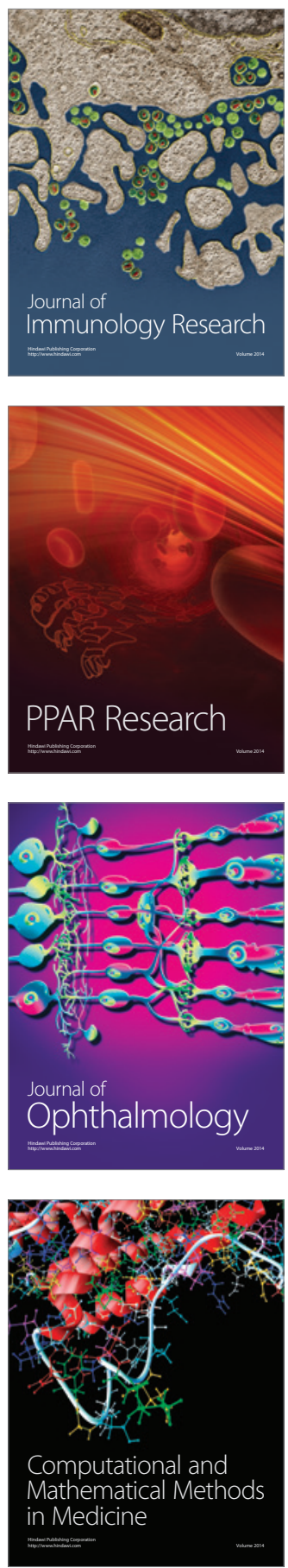

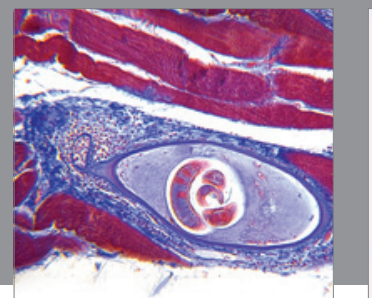

Gastroenterology

Research and Practice
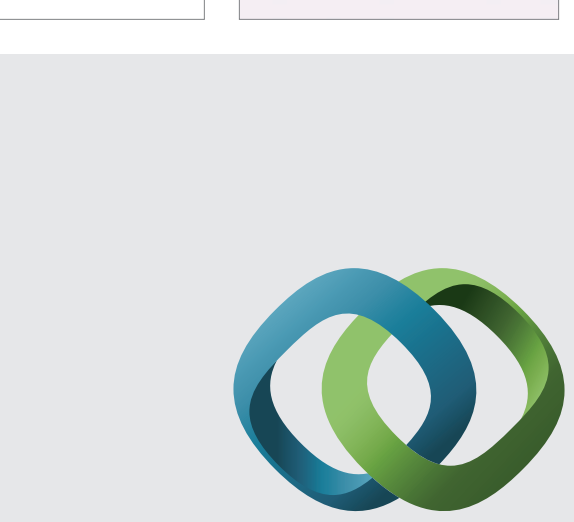

\section{Hindawi}

Submit your manuscripts at

http://www.hindawi.com
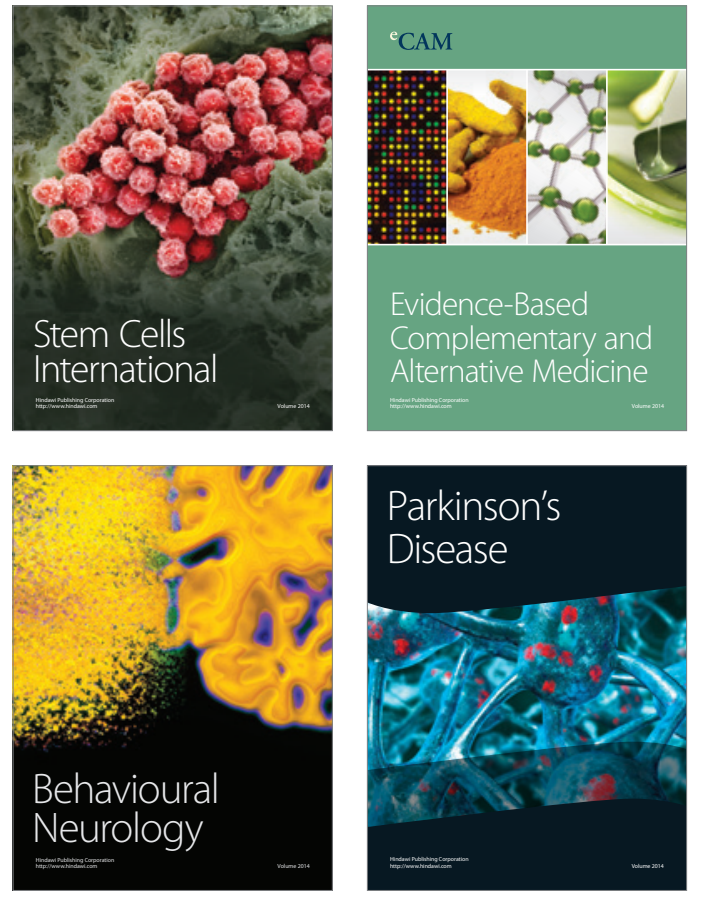
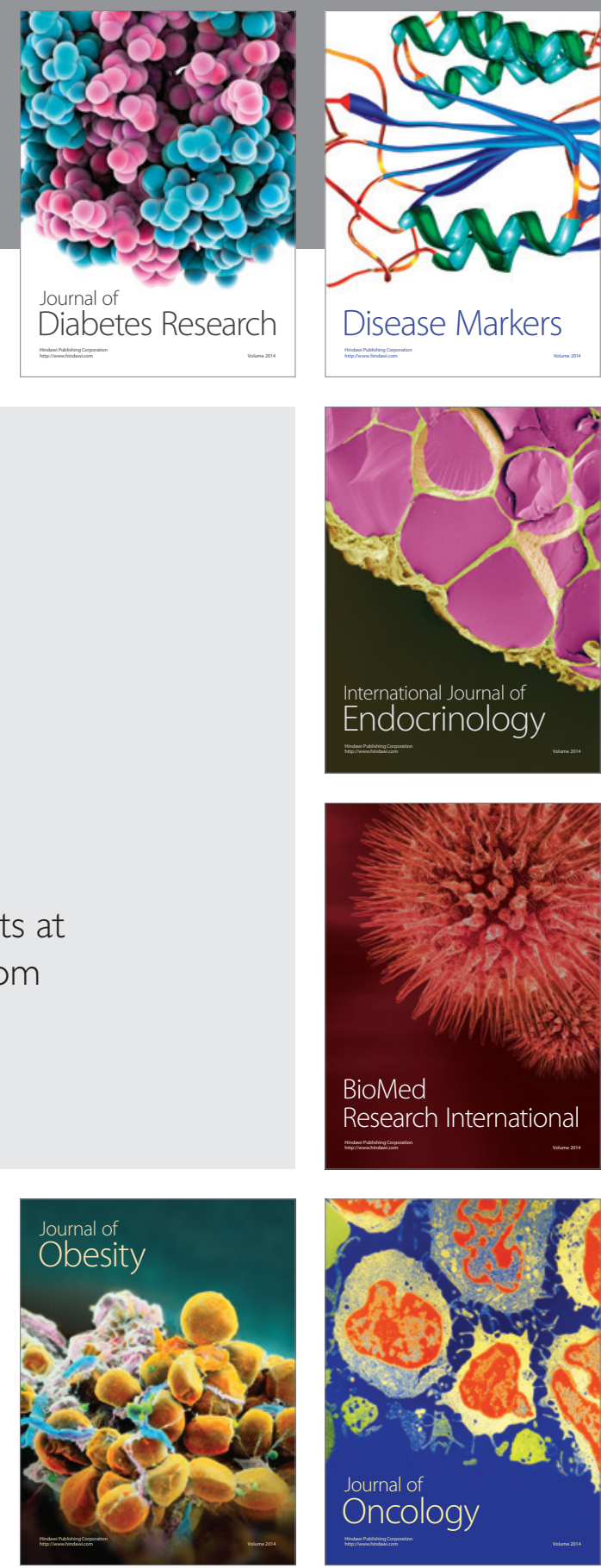

Disease Markers
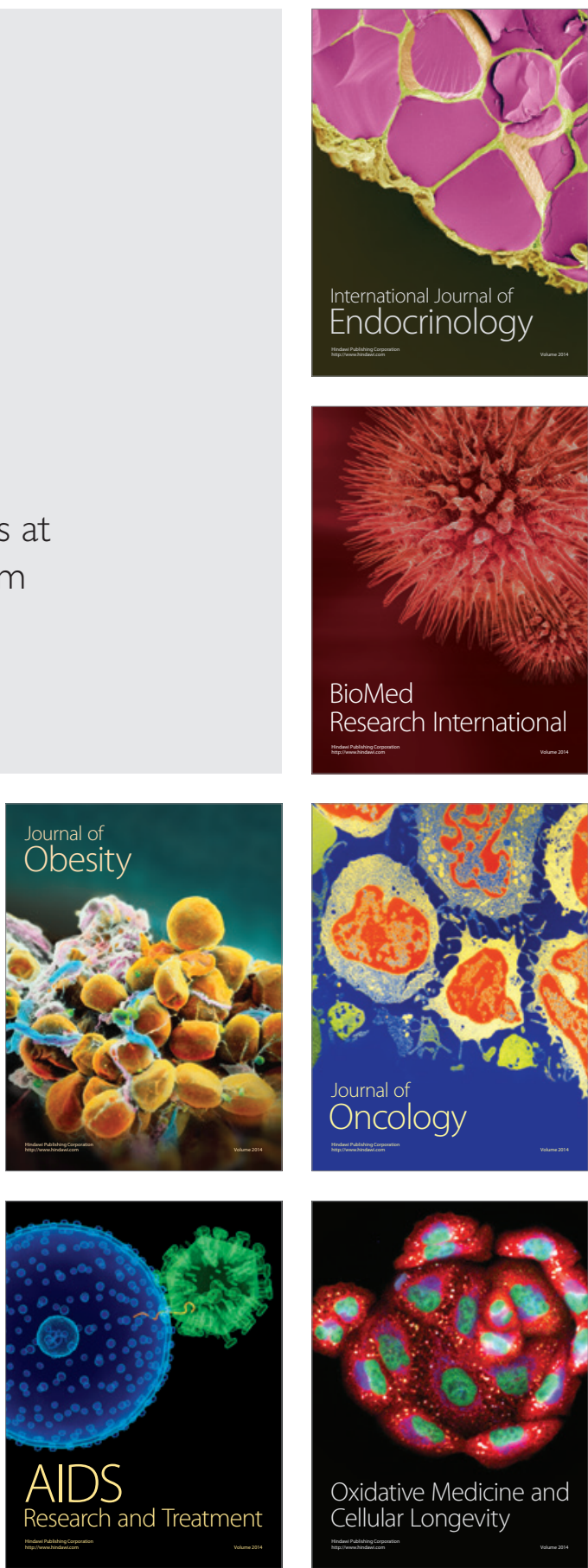